\title{
Pandemic Windfalls and Obligations of Justice
}

\author{
BRIAN BERKEY \\ University of Pennsylvania
}

\begin{abstract}
The Covid-19 pandemic has caused significant economic hardships for millions of people around the world. Meanwhile, many of the world's richest people have seen their wealth increase substantially during the pandemic, despite the significant economic disruptions that it has caused on the whole. It is uncontroversial that these effects, which have exacerbated already unacceptable levels of poverty and inequality, call for robust policy responses from governments. In this paper, I argue that the disparate economic effects of the pandemic also generate direct obligations of justice for those who have benefitted from pandemic windfalls. Specifically, I argue that even if we accept that those who benefit from distributive injustice in the ordinary, predictable course of life within unjust institutions do not have direct obligations to redirect their unjust benefits to those who are unjustly disadvantaged, there are powerful reasons to hold that benefitting from pandemic windfalls does ground such an obligation.
\end{abstract}

Keywords: Covid-19, distributive justice, inequality, institutions, poverty, windfalls

JEL Classification: A13, D31, D63, D64, E24, I30

\section{INTRODUCTION}

The Covid-19 pandemic has caused significant economic hardships for millions of people around the world. In the United States alone, it is estimated that the number of citizens living in poverty grew by 8.1 million between June and December of 2020 (Han, Meyer, and Sullivan 2021). ${ }^{1}$

\footnotetext{
${ }^{1}$ It is worth noting that the poverty rate in the United States did decline modestly between January and June of 2020 (Han, Meyer, and Sullivan 2021), most likely due to a combination of Earned Income Tax Credit payments, CARES Act stimulus checks, and the expanded unemployment benefits also provided under the CARES Act (Perolin et al. 2020, 4-5). Nonetheless, there was still a significant increase overall between January and December, and the large increase between June and December coincided with a $40 \%$ reduction in the unemployment rate (Han, Meyer, and Sullivan 2021). The
} 
This increase is primarily the result of lost income from paid labor, ${ }^{2}$ combined with the lack of a government policy response that would sufficiently offset these losses to prevent people from falling into poverty. Many people have lost their jobs, while others have had their hours reduced, or found their opportunities to earn money through work in the 'gig economy' curtailed. The economic losses that Americans have suffered as a result of the pandemic have, to a large degree, been experienced by the poor and the working class. ${ }^{3}$

Globally, it is estimated that the pandemic could increase the number of people living below the World Bank's $\$ 5.50$ per day poverty threshold by between 200 and 500 million (Berkhout et al. 2021, 24). ${ }^{4}$ More generally, there is evidence that the pandemic will increase inequality throughout much of the world (World Bank 2020, xi), and that the poorest people in virtually every country will experience a drop in their incomes (Christensen and Wells 2020, 8-9).

Meanwhile, as has been widely reported, many of the world's richest people have seen their wealth increase substantially during the pandemic, despite the significant economic disruptions that it has caused on the whole. The world's billionaires gained nearly $\$ 4$ trillion in wealth between March and December of 2020 (Berkhout et al. 2021, 23). Elon Musk alone gained nearly $\$ 129$ billion in those ten months, while Jeff Bezos gained over $\$ 78$ billion (Berkhout et al. 2021, 23).

In addition, while other well-off people have not experienced the massive gains that billionaires have captured, those in the upper middle class or higher in the income distribution in wealthy countries have largely avoided significant losses from the pandemic. ${ }^{5}$ One important reason for this is that these people are more likely to have jobs that they can perform from home, and so are less likely to have lost their jobs or had their hours

discontinuation of the expanded unemployment benefits at the end of July contributed to the rise in poverty observed in the second half of the year (Perolin et al. 2020, 5). It is also worth noting that as of September of 2020, the poverty rate among Black and Hispanic Americans had increased by 1-2 percentage points more than the increase observed among White Americans, in comparison with pre-pandemic levels (Perolin et al. 2020, 8-9).

${ }^{2}$ More than 93 million unemployment insurance claims have been filed in the United States during the pandemic (Han, Meyer, and Sullivan 2021).

${ }^{3}$ From February to mid-May of 2020, employment among Americans in the bottom 25\% of wage earners fell by 35\% (Timiraos 2020).

${ }^{4}$ For the lower estimate, see Lakner et al. (2020); for the higher, see Sumner, Ortiz-Juarez, and Hoy $(2020,8)$.

${ }^{5}$ In the UK, for example, those in the top $20 \%$ of the income distribution have saved $\$ 30$ billion since March of 2020, while those with lower incomes have tended to fall (further) into debt (Berkhout et al. 2021, 24). 
or pay cut. While the pandemic may not have increased the income of most of these people, it has benefitted many of them economically, since they have been able to avoid commuting costs, and have been able to save more money in virtue of the more limited availability and attractiveness of, for example, the leisure activities on which they typically spend some of their income.

The pandemic, then, has generated substantial economic windfalls for many of the world's better-off people, while at the same time causing significant economic hardships to befall many of the worst-off citizens in nearly every country. It is relatively uncontroversial that these effects, which have exacerbated already unacceptable levels of poverty and inequality, call for robust policy responses from governments. Justice requires, for example, that states provide income supplements to those who have been thrust into poverty, and that they take steps to prevent people from becoming homeless (for example, by adopting eviction moratoriums). ${ }^{6}$

In the remainder of this paper, I argue that the disparate economic effects of the pandemic (that is, windfalls for the already well-off and increased hardships for the poor and working class) also generate direct obligations of justice for those who have benefitted from pandemic windfalls. Specifically, I argue that even if we accept that those who benefit from distributive injustice in the ordinary, predictable course of life within unjust institutions do not have direct obligations to redirect their unjust benefits to those who are unjustly disadvantaged, there are powerful reasons to hold that benefitting from pandemic windfalls does ground such an obligation.

I proceed in the remainder of the paper as follows. First, in section II, I clarify how, for the purposes of the paper, I understand what constitutes a windfall. In addition, I explain, with reference to the two most prominent views about the kinds of factors that determine the justice or injustice of a distribution, the relationship between windfalls and distributive justice. Next, in section III, I argue that on either view about the kinds of factors that determine the justice/injustice of a distribution, there are compelling grounds for accepting that beneficiaries of pandemic windfalls are obligated to redirect their windfall benefits in ways that will improve the lives of those who are unjustly disadvantaged. I conclude, in

\footnotetext{
${ }^{6}$ These requirements apply on top of standing requirements to raise citizens out of poverty, ensure decent housing for the homeless, etc.
} 
section IV, by briefly noting the central implications of my argument with respect to the current pandemic.

\section{DISTRIBUTIVE JUSTICE AND WINDFALLS}

In colloquial terms, windfalls are economic gains that are not the result of careful or strategic planning for the event or events that caused those gains to obtain. Typically, only at least moderately large gains are described as windfalls. If I find a $\$ 10$ bill while walking down the street, it would seem an exaggeration to claim that I have received a windfall. Windfalls are often unexpected and unpredictable, though they need not be. Examples of economic gains that intuitively count as windfalls include substantial lottery winnings (which are unexpected and unpredictable) and large inheritances (which in some cases are both expected and predictable).

For the purposes of this paper, I will limit my account of what constitutes a windfall to significant economic gains that are not the result of (relevant forms of) careful or strategic planning, and are either: (1) enjoyed by those who were not unjustly disadvantaged prior to the receipt of those gains; or (2) enjoyed by those who were unjustly disadvantaged prior to the receipt of the gains, but large enough that they improve the economic position of the beneficiaries to an extent that they become unjustly advantaged. ${ }^{7}$ In addition, within the second category, I take the portion of a person's gains that constitutes a windfall to be limited to that which makes it the case that she becomes unjustly advantaged on the whole. So, for example, if a person who initially possessed no wealth at all, and was therefore unjustly disadvantaged, wins $\$ 500,000$ in the lottery, then the amount of her windfall is $\$ 500,000$ minus whatever amount she ought to have had as a matter of justice initially (so, if she ought to have had $\$ 100,000$, then she received a $\$ 400,000$ windfall). This characterization of windfalls ensures that my claim that individuals are obligated to redirect windfall benefits does not imply that anyone will ever

\footnotetext{
${ }^{7}$ Some might worry that counting gains in this second category as windfalls begs the question in favor of my view. But importantly, the fact that one is unjustly advantaged does not by itself imply that one has direct obligations to redirect their unjust benefits to the unjustly disadvantaged. In fact, as my discussion will show, many philosophers reject this view. What does follow, on virtually all views of what is required when some are unjustly advantaged while others are unjustly disadvantaged, is that the state ought to adopt policies that will remedy the relevant injustice, without infringing other requirements of justice (for example, by increasing taxes on the unjustly advantaged and using the funds generated in ways that benefit the unjustly disadvantaged). My argument relies only on this view about appropriate state responses to injustice.
} 
be obligated to redirect resources that they ought to possess as a matter of justice.

In order to clarify how we might understand the relationship between windfalls and distributive justice, it is important to consider what kinds of factors might determine the justice or injustice of distributions. There are two prominent views about this question in political philosophy. On the first type of view, distributive justice is fundamentally about outcomes, and requires that the distribution of resources satisfies a substantive criterion or set of criteria (Cohen 2008, 126). ${ }^{8}$ The sufficientarian view that a distribution is just if and only if everyone has sufficient resources to live a flourishing life is an example of a view of this kind, as is the luck egalitarian view that a distribution is just if and only if there are no inequalities that reflect differences in luck rather than choice. ${ }^{9}$

To illustrate what will count as a windfall on views of this kind, consider the sufficientarian view as an example. On this view, a person has benefitted from a windfall (1) if she already had sufficient resources to live a flourishing life and then experiences a significant economic gain that is not the result of careful or strategic planning on her part, or (2) if she experiences a significant economic gain that is not the result of strategic planning on her part and that moves her from being unjustly disadvantaged to being unjustly advantaged. On plausible views, she will count as unjustly advantaged after receiving a significant gain if, for example, the state would be justified in increasing her tax burden in order to provide resources to those who are unjustly disadvantaged. Importantly, this criterion for when a person is unjustly advantaged can be applied in conjunction with any outcome-focused account of distributive justice.

According to the second type of view about the factors that determine the justice or injustice of a distribution, distributive justice is fundamentally procedural rather than outcome-focused. On views of this kind, justice requires that procedures that meet certain conditions are implemented, and a distribution is just if it results from those procedures being

\footnotetext{
${ }^{8}$ Views of this type need not take resources to be the metric or 'currency' of justice (Cohen 1989). Instead, they can hold that the distribution of resources must ensure that another currency, such as welfare or capabilities, is distributed in a way consistent with justice.

${ }_{9}^{9}$ Some philosophers who are sufficientarians or luck egalitarians do not accept an outcome-focused account of distributive justice, and instead hold that, for example, a distribution is just if relevant institutional procedures ensure, as much as possible, that everyone has sufficient resources to live a flourishing life, or that inequalities that reflect differences in luck are limited. For my purposes, the important thing is that views of the first type apply the criteria of distributive justice (whatever those criteria are) directly to distributive outcomes.
} 
properly followed. Robert Nozick's libertarian account of justice in "holdings" (1974, chap. 7) is a view of this kind, as is John Rawls's "pure procedural" $(1999,74-77)$ account of distributive justice, according to which a distributive outcome is just, "whatever it is" (1999, 75), so long as the institutions of the "basic structure of society" (1999, 6-9) have adopted policies consistent with his two principles of justice, and those policies have been properly followed. ${ }^{10}$

On views of this kind, a person has benefitted from a windfall (1) if she already had at least as much as she would have had with just procedures in place, and then experiences a significant economic gain that is not the result of careful or strategic planning on her part, or (2) if she experiences a significant economic gain that is not the result of strategic planning on her part and that moves her from having less than she would have had with just procedures in place to having more than she would have had with just procedures in place.

It is important to note that while I have defined windfalls in terms of economic gains, my argument does not require that the correct metric or currency of justice is one on which economic resources are a direct component (for example, Dworkin's 1981 resourcist view, or Rawls's 1999 account of primary social goods). ${ }^{11}$ This is because I have defined windfalls so that only gains in economic resources that leave one with more than she is entitled to as a matter of justice can constitute windfall gains. Even if, for example, welfare is the currency of justice (Arneson 2000), or a component of the currency of justice (Cohen 1989), it is resources that must be distributed in order to ensure that individuals' entitlements of justice are satisfied-welfare is not directly distributable. Because of this, even if the share of economic resources to which one is entitled, as a matter of justice, is itself determined at least in part by the way in which her welfare would be affected by different economic distributions, it will nonetheless be the case that there is some particular share of resources to which she is entitled. And since the share of resources to which she is entitled will itself be a function, at least in part, of how resource shares would, for her, map onto (expected) welfare levels-if she were to receive a windfall, and therefore have more resources than she is entitled to as a matter of justice, then she would also tend to have more (expected)

\footnotetext{
${ }^{10}$ The most compelling evidence that Rawls viewed the relevant procedural requirements as both necessary and sufficient for distributive justice can be found in Political Liberalism (1993, 282). For criticism, see Murphy (1998, 287), and Berkey (2015; 2016, 715-718; 2018, 730-732, 744-747; 2021, 183-185, 197-204).

${ }^{11} \mathrm{I}$ am grateful to an anonymous reviewer for encouraging me to clarify this point.
} 
welfare than she is entitled to. ${ }^{12}$ Because this is the case, my argument will not imply that it is possible for one to receive a windfall and yet have less than one is entitled to in terms of welfare (or any other non-resourcist possible currency of justice). ${ }^{13}$

It is also worth noting that while my account of what constitutes a windfall relies on a distinction between gains that result from (relevant forms of) careful and strategic planning and those that do not, I do not and cannot here provide a complete account of how this distinction should be understood. And while I suspect that in some cases it will be relatively uncontroversial that gains either are or are not the result of careful and strategic planning, there are a number of issues that a complete account would require taking a position on that would be relevant to assessing more difficult cases. For example, we would need to take a position on whether the fact that one has engaged in careful and strategic planning for purposes other than achieving economic gains makes it the case that gains that one obtains as a result do not constitute a windfall. In other words, we would need to determine whether one must be intentionally pursuing economic gains in particular in order for her careful and strategic planning to render any gains that she obtains exempt from the obligation to redirect windfall gains. In addition, we would need to take a position on whether careful and strategic planning that aimed to generate economic gains in one way, but which happens to generate gains in a different, entirely unexpected and unplanned way, makes it the case that the gains do not count as a windfall. My own inclinations tend toward a fairly

\footnotetext{
${ }^{12}$ This is because, all else being equal, increases in resources tend to generate increases in (expected) welfare. The exceptions will be cases in which a person's gaining in terms of resources would have no effect on her expected welfare level. This is likely true for many, if not most, of the very wealthy. In these cases, those who hold that welfare is the currency of justice, or a significant component of that currency, should be especially inclined to think that those who receive windfalls are obligated to redirect them to people who are unjustly disadvantaged.

${ }^{13}$ It might be objected that at least some people who have received economic windfalls during the pandemic have nonetheless been made worse off in terms of welfare, so that despite having more resources than they are entitled to, they have less welfare than they did previously, and perhaps less than they were entitled to as a matter of justice. However, while it is likely true that some people who have received windfall economic benefits during the pandemic have nonetheless suffered greater overall welfare losses than most others, the fact that the pandemic has negatively affected the welfare of the vast majority of people makes it the case that those who were quite well off before the pandemic will, on welfarist or partially welfarist views, be entitled to less in terms of welfare than they were previously-there is simply less (potential) welfare that can be achieved in a world dealing with a global pandemic. Because of this, at least many who have received windfalls will, if my argument is right, be obligated to redirect at least some of these gains, even if they have been made worse off in terms of welfare.
} 
broad account of when gains count as windfalls, so that plans that unintentionally produce gains, and plans that produce gains in unplanned ways, do not exempt the gains from the requirement to redirect windfalls. A full defense of this view, however, must be left for another occasion.

\section{PANDEMic WindFAlls AND Obligations OF JuSTiCE}

On outcome-focused accounts of distributive justice (for example, sufficientarianism), the case for the obligation to redirect windfall gains is fairly straightforward. First, since any redirection of resources from a person who has more than she is entitled to as a matter of justice to someone who has less than she is entitled to would make the resulting distribution less unjust, there is always at least some moral reason in favor of the redirection. In order for it to be permissible to refrain from redirecting, then, a justification is required that is sufficient to counteract the force of the reason in favor. Perhaps the most plausible justification that could be offered for refraining from redirecting resources that one possesses beyond what she is entitled to as a matter of justice is that one has, within an admittedly unjust system, carefully and strategically made choices that resulted in gains beyond one's justice-based entitlements, in order to limit one's risk of becoming one of the people that the unjust system allows to be unjustly disadvantaged. If this justification is offered alongside the acknowledgement that one is, along with everyone else, obligated to work to make the system just (or at least less unjust),,$^{14}$ even if the success of that effort would result in, for example, one's becoming subject to increased taxation, it is at least not obvious that it should be re-

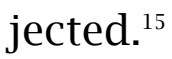

This justification, however, is not available in the case of windfalls. By their nature, windfall gains are not attributable to careful and strategic planning on the part of those who benefit from them. Instead, they result from simple good fortune. When one experiences good fortune that renders her better off than she is entitled to be as a matter of justice, while others who are unjustly disadvantaged suffer severe hardships, the

\footnotetext{
${ }^{14}$ See, for example, Rawls's discussion of the "natural duty of justice", which requires us to "further just arrangements not yet established, at least when this can be done without too much cost to ourselves" $(1999,99)$.

${ }^{15}$ Because on outcome-focused accounts, redirections from the unjustly advantaged to the unjustly disadvantaged necessarily constitute improvements with respect to justice, this justification cannot plausibly succeed in cases in which individuals, even as a result of their own careful and strategic planning within an unjust system, possess vastly more resources than they are entitled to as a matter of justice, while others are unjustly extremely badly off.
} 
reasons for thinking that she is obligated to redirect her windfall benefits seem especially strong. When an event such as a global pandemic (perhaps in combination with inadequate policy responses from governments) consistently delivers good fortune to those who were already very well off (and, on essentially all plausible views unjustly advantaged), while at the same time making millions of poor and working class people worse off than they were (and therefore even more unjustly disadvantaged), the prospects for justifying refusal by the beneficiaries to redirect their windfall gains seem dim. The gains in terms of justice would be too great, and the grounds that they might offer for refusing are too limited and implausible.

It is, however, somewhat less clear that an obligation to redirect windfall gains can be defended within procedural accounts of distributive justice. This is because, on these accounts, redirection (from those with more than they are entitled to as a matter of justice to those with less) that is not accomplished via the procedures that constitute the fundamental requirements of justice need not count as making the resulting distribution any less unjust than the initial distribution. If a just distribution is defined as a distribution that results from the following of just procedures, then even if their tendency to bring about distributive outcomes with certain substantive features is what makes particular procedures the ones required by justice (as is the case on Rawls's view), actions that bring about similar results by means that do not run through the required procedures, such as direct transfers from well-off individuals to badly-off individuals, cannot, as a conceptual matter, make a distribution less unjust.

Procedural accounts are often motivated by the thought that distributive justice is fundamentally the responsibility of state institutions, and not of agents acting within those institutions, such as individuals or firms (Rawls 1993, 268-269). Proponents of these accounts typically hold that while individuals and other non-state agents are obligated to contribute to transforming unjust procedures into just ones, they are not obligated, as a matter of justice, to redirect unjust advantages that they possess in virtue of the operation of existing unjust procedures to those who are unjustly disadvantaged by the operation of those procedures. This is, on these views, part of what follows from the view that distributive justice is fundamentally the responsibility of state institutions rather than agents acting within them. 
As I suggested above with respect to outcome-focused accounts, it might be argued that when individuals are able, through careful and strategic planning, to acquire more in the way of resources within an unjust system than they would have been able to acquire had the system been just, they are permitted to refrain from redirecting what they possess beyond their just entitlements to those who are unjustly disadvantaged. We might think, for example, that when unjust advantages and disadvantages occur as a predictable result of flawed policies implemented by states, individuals' conscientious efforts to improve their own lives within the unjust system entitle them to keep what they have acquired, at least so long as they also satisfy their obligation to support the institutional changes required by justice.

Even if this line of argument is defensible, however, it does not provide grounds for concluding that individuals are permitted to refrain from redirecting windfall gains. There are at least two reasons to doubt that this extension can be defended. First, windfall gains are not attributable to individuals' conscientious efforts within an admittedly unjust system, but instead result from (often unpredictable) good fortune. In these cases, the same reasons that explain why policies that tend to bring about certain distributive outcomes are the ones required by justice will also support individual obligations to redirect gains, and these reasons will not be counterbalanced by reasons in favor of a permission not to do so grounded in individuals' conscientious efforts to realize those gains.

More importantly, however, at least some windfall gains, including those that have resulted from the pandemic, are not outcomes that it is reasonable to expect state policies to be designed to fully prevent ex ante. State policies must be designed to predictably bring about just results, as much as possible, in the ordinary course of life in a society. Of course, generally applicable policies can and should be adopted that aim, broadly speaking, to mitigate the negative effects of unpredictable events such as the pandemic. But no such policies can be expected to be able to fully redress the negative, justice-relevant effects of every possible large-scale unpredictable event or set of events. Instead, as we have seen during the pandemic, states must respond to such events, as they are happening, with policies that aim to limit their negative effects. And implementing such policies takes time, even when states are functioning reasonably well. This leaves those who suffer unpredictable and unjust disadvantages unavoidably waiting for relief, which may or not be forthcoming. Those who enjoy windfall gains can help provide the required relief by 
redirecting those gains to the unjustly disadvantaged. ${ }^{16}$ Because it is not possible for policies to be designed in advance that could reliably and fully redress the negative effects of any unpredictable event such as a pandemic, the reasons that might generally justify attributing exclusive direct responsibility for ensuring distributive justice to states do not apply in cases involving large-scale unpredictable windfall gains for some and significant losses for others.

\section{CONCLUSION}

If my argument in the previous section is correct, then those who have received windfall gains as result of the pandemic are obligated to redirect those gains in ways that would benefit the unjustly disadvantaged. Importantly, there are reasons to think that it is not just billionaires such as Musk and Bezos that have received such gains. ${ }^{17}$ Many of those who are well off but far from billionaires likely have as well. If one has not lost her job or had her pay cut, has enjoyed more limited transportation expenses in virtue of working from home, and perhaps owns some stock, the value of which has been propped up by government policies, while less has been done to protect the poor and working class from the effects of the pandemic, it seems likely that she has received at least some windfall gains, and is obligated, if I am right, to redirect them.

\section{REFERENCES}

Arneson, Richard J. 2000. "Welfare Should be the Currency of Justice." Canadian Journal of Philosophy 30 (4): 497-524.

Berkey, Brian. 2015. "Double Counting, Moral Rigorism, and Cohen's Critique of Rawls: A Response to Alan Thomas." Mind 124 (495): 849-874.

Berkey, Brian. 2016. “Against Rawlsian Institutionalism about Justice.” Social Theory and Practice 42 (4): 706-732.

\footnotetext{
${ }^{16}$ As an anonymous reviewer rightly points out, not every case in which one receives windfall gains is one in which individuals will be able to act to aid those who are unjustly disadvantaged before governments can. For example, the stimulus checks that many Americans have received may constitute windfall gains for some, but of course they cannot redistribute those gains until the government sends them the funds. This is, however, an example in which policy likely cannot be calibrated in a short period of time to reliably direct all of the relevant funds in the ways require by justice-a blunt policy that simply sends checks to all citizens with incomes below a certain threshold may be the best that can be done in short order. But because this policy will unavoidably result in windfall gains for some, there are reasons to think that there can be obligations to directly redistribute those gains to those who remain unjustly disadvantaged.

${ }^{17}$ While it seems to me quite unlikely that those like Musk and Bezos have received no windfall gains as a result of the pandemic, it is of course difficult to estimate how much of any particular person's gains during the relevant period constitute windfall gains.
} 
Berkey, Brian. 2018. "Obligations of Productive Justice: Individual or Institutional?" Critical Review of International Social and Political Philosophy 21 (6): 726-753.

Berkey, Brian. 2021. "Rawlsian Institutionalism and Business Ethics: Does it Matter Whether Corporations are Part of the Basic Structure of Society?" Business Ethics Quarterly 31 (2): 179-209.

Berkhout, Esmé, Nick Galasso, Max Lawson, Pablo Andrés Rivero Morales, Anjela Taneja, and Diego Alejo Vásquez Pimentel. 2021. "The Inequality Virus: Bringing Together a World Torn Apart by the Coronavirus through a Fair, Just and Sustainable Economy." Oxfam Briefing Paper. Oxfam International, Oxford.

Christensen, Zach, and Claudia Wells. 2020. "How is Covid Impacting People Living in Poverty Worldwide?” Development Initiatives Briefing. Development Initiatives, Bristol.

Cohen, Gerald A. 1989. "On the Currency of Egalitarian Justice." Ethics 99 (4): 906-944.

Cohen, Gerald A. 2008. Rescuing Justice and Equality. Cambridge, MA: Harvard University Press.

Dworkin, Ronald. 1981. "What is Equality? Part 2: Equality of Resources." Philosophy \& Public Affairs 10 (4): 283-345.

Han, Jeehoon, Bruce D. Meyer, and James X. Sullivan. 2021. "Real-time Poverty Estimates During the COVID-19 Pandemic through December 2020." Poverty Measurement, January 20, 2021. http://povertymeasurement.org/wp-content/uploads/2021/01/ Real_time_Poverty_Estimates_through_December_2020.pdf.

Lakner, Christoph, Nishant Yonzan, Daniel Gerszon Mahler, R. Andrés Castañeda Aguilar, Haoyu Wu, and Melina Fleury. 2020. "Updated Estimates of the Impact of COVID19 on Global Poverty: The Effect of New Data." World Bank Data Blog, October 7, 2020. https://blogs.worldbank.org/opendata/updated-estimates-impact-covid-19global-poverty-effect-new-data.

Murphy, Liam B. 1998. "Institutions and the Demands of Justice." Philosophy \& Public Affairs 27 (4): 251-291.

Nozick, Robert. 1974. Anarchy, State, and Utopia. New York, NY: Basic Books.

Perolin, Zachary, Megan Curran, Jordan Matsudaira, Jane Waldfogel, and Christopher Wimer. 2020. "Monthly Poverty Rates in the United States during the COVID-19 Pandemic." Poverty and Social Policy Working Paper. Center on Poverty and Social Policy, New York, NY.

Rawls, John. 1993. Political Liberalism. New York, NY: Columbia University Press.

Rawls, John. 1999. A Theory of Justice. Revised Edition. Cambridge, MA: The Belknap Press of Harvard University Press.

Sumner, Andy, Eduardo Ortiz-Juarez, and Chris Hoy. 2020. "Precarity and the Pandemic: COVID-19 and Poverty Incidence, Intensity, and Severity in Developing Countries." Working Paper No. 2020/77. World Institute for Development Economics Research (UNU-WIDER), Helsinki.

Timiraos, Nick. 2020. "Fed Report Says Coronavirus Shock Has Hit Low-Wage Workers Hardest.” Wall Street Journal, June 12, 2020. https://www.wsj.com/articles/fed-report-says-coronavirus-shock-has-hit-low-wage-workers-hardest-11591985092.

World Bank. 2020. "Poverty and Shared Prosperity 2020: Reversals of Fortune." World Bank Group Report. World Bank, Washington, DC. 
Brian Berkey is Assistant Professor in the Legal Studies and Business Ethics Department in the Wharton School at the University of Pennsylvania, and holds a secondary appointment in the Penn Philosophy Department. He works in moral and political philosophy, including environmental and business ethics, and has published articles on moral demandingness, individual and corporate obligations of justice, climate change ethics, exploitation, effective altruism, collective obligations, and animal ethics. Contact e-mail: <bberkey@wharton.upenn.edu> 